\title{
BMJ Open Evaluation of Mediterranean diet adherence scores: a systematic review
}

\author{
A Zaragoza-Martí, ${ }^{1}$ MJ Cabañero-Martínez, ${ }^{1}$ JA Hurtado-Sánchez, ${ }^{1}$ \\ A Laguna-Pérez, ${ }^{1}$ R Ferrer-Cascales ${ }^{2}$
}

To cite: Zaragoza-Martí A, Cabañero-Martínez MJ, Hurtado-Sánchez JA, et al. Evaluation of Mediterranean diet adherence scores: a systematic review. BMJ Open 2018;8:e019033. doi:10.1136/ bmjopen-2017-019033

- Prepublication history and additional material for this paper are available online. To view these files, please visit the journal online (http://dx.doi. org/10.1136/bmjopen-2017019033).

Received 9 August 2017 Revised 23 November 2017 Accepted 4 January 2018

Check for updates

${ }^{1}$ Department of Nursing, Faculty of Health Sciences, University of Alicante, Alicante, Spain

${ }^{2}$ Department of Health

Psychology, Faculty of Health

Sciences, University of Alicante, Alicante, Spain

Correspondence to

MJ Cabañero-Martínez;

mariajose.cabanero@ua.es and

R Ferrer-Cascales;

rosario.ferrer@ua.es

\begin{abstract}
Objective The aim of this review was to evaluate the conceptual suitability, applicability and psychometric properties of scores used internationally to measure adherence to the Mediterranean diet (MD).
\end{abstract}

Design This was a systematic review to identify original articles that examined some aspects of the conceptual suitability, applicability or psychometric properties of the MD adherence score. Electronic searches were carried out on the international databases MEDLINE, Scopus, Web of Science and EMBASE (from January 1980 to 31 December 2015).

Eligibility criteria for selecting studies The study included original articles that examined some aspects of the conceptual suitability, applicability or psychometric properties of the MD adherence score. The studies where MD adherence scores were administered but did not bring forward any evidence about their performance related to conceptual suitability, applicability or psychometric properties were excluded.

Data extraction Information relating to the scales was extracted in accordance with the quality criteria defined by the Scientific Advisory Committee of the Medical Outcomes Trust for measurement of health results and the quality criteria recommended by Terwee: (1) conceptual, (2) applicability and (3) psychometric properties. Three authors independently extracted information from eligible studies.

Results Twenty-seven studies were identified as meeting the inclusion criteria, yielding 28 MD adherence scores. The results showed that evidence is scarce and that very few scores fulfilled the applicability parameters and psychometric quality. The scores developed by Panagiotakos et al, Buckland et al and Sotos-Prieto et al showed the highest levels of evidence.

Conclusions Scores measuring adherence to MD are useful tools for identifying the dietary patterns of a given population. However, further information is required regarding existing scores. In addition, new instruments with greater conceptual and methodological rigour should be developed and evaluated for their psychometric properties.

\section{INTRODUCTION}

Several epidemiological studies have evaluated the relationship between health and food intake. ${ }^{1-6}$ Specifically, various population surveys and clinical trials provide evidence that diets that are high in fruits,

\section{Strengths and limitations of this study}

- This systematic review represent, to our knowledge, the most comprehensive examination of the evidence on the conceptual suitability, applicability and psychometric properties of scores used internationally to measure adherence to the Mediterranean diet (MD).

- Twenty-seven studies were identified as meeting the inclusion criteria, yielding $28 \mathrm{MD}$ adherence scores. The results showed that evidence is scarce and that very few scores fulfilled the applicability parameters and psychometric quality.

- This review only took account of studies wherein the main objective was to develop or examine data about the applicability or psychometric properties of an MD adherence score. It could produce an underestimation of the predictive and/or concurrent validity, which are the most frequently analysed in longitudinal studies on MD adherence scores.

- Future research should focus on improving the psychometric properties of the MD adherence scores, and analysing the concordance between these instruments in compliance with the normative quality criteria.

vegetables, legumes, whole grains and fish, and moderate in dairy intake, are associated with lower incidence of chronic diseases. ${ }^{47-10}$

The Mediterranean diet (MD) is characterised by a high intake of plant-based foods (vegetables, legumes, fruits, nuts, cereals (mainly whole grain)), olive oil as the main source of fat, moderate amounts of dairy (yoghourt and cheese), low or moderate consumption of fish and meat, moderate consumption of wine consumed with meals, and an active lifestyle. ${ }^{11-14}$ Although the various geographical regions of the Mediterranean have different diets, influenced by sociocultural, religious or economic factors, among others, it can be assumed that these diets are variations of the same MD diet. ${ }^{1516}$

Various longitudinal studies have analysed the benefits of MD in comparison with other types of diet. ${ }^{17-23}$ These studies have shown that people with good adherence to MD have 
a better quality of life and greater life expectancy, along with a decreased prevalence of chronic diseases such as certain types of cancer, type 2 diabetes, and cardiovascular or neurodegenerative diseases. ${ }^{151024-27}$ Specifically, the protective role of MD has been attributed to the high intake of plant-based foods, along with a moderate consumption of wine, fish and dairy, and a high intake of monounsaturated fatty acids in lieu of saturated and trans fatty acids, which are linked with an elevated antioxidant capacity. ${ }^{810}$ Therefore, it is important to ascertain the degree of adherence to MD through accurate measurement tools such as dietary scores based on the frequency of pattern-consistent and pattern-inconsistent food consumption, as well as compliance with recommended intake. ${ }^{28}$

Evidence shows that dietary scores are useful tools to evaluate the degree of adherence to MD and its benefits in regard to health. Scores are composite constructs based on dietary components, combining foods and nutrients to obtain valid operational variables that analyse the association between the quality of diet and its health effects. ${ }^{29}$ Several scores are used to measure the degree of agreement with MD. The first and most widely used score was created by Trichopoulou et al in $1995 .^{30}$ This score evaluates concordance with the dietary pattern, by assigning one point when the intake of protective foods is higher than the median, in the study/sample population, or when the consumption of non-protective foods is lower than the median, and zero in the opposite situations. Other scores based on MD have been created for use in different geographical populations, for populations with different underlying physiological states, so that alternate foods can be incorporated into and/or accounted for within the canonical pattern. ${ }^{11} 31-34$

The characteristics of MD scores have been reviewed in different studies. ${ }^{15}{ }^{35}$ However, the quality of these instruments, which is fundamental to ensuring their valid and reliable application, has not been analysed. The heterogeneity of MD adherence scores raises the potential for disparity in analyses, as well as confusion as to which specific score to choose. Therefore, to be able to select a good instrument, one must first know the quality criteria it offers. Knowledge of such criteria is imperative for the accurate use of the instrument. ${ }^{36-39}$ According to the Scientific Advisory Committee (SAC) of the Medical Outcomes Trust, eight quality criteria must be established, corresponding to three groups of information: conceptual suitability (conceptual and measurement model, cultural and linguistic adaptation); applicability (demands of the administrator and respondent, alternative forms, interpretability); and psychometric properties (reliability, validity and responsiveness). ${ }^{39}$

For this reason, the aim of this review was to evaluate the conceptual suitability, applicability and psychometric properties of MD adherence scores used internationally.

\section{METHODOLOGY \\ Search strategy}

To obtain original documents, electronic searches were carried out using the following international databases: MEDLINE, Scopus, Web of Science and EMBASE. The search strategy was designed to obtain original studies about the development or validation of scores measuring adherence to MD, published until 31 December 2015 (January 1980 to 31 December 2015). This strategy focused on combining the following keywords: Mediterranean diet, score and adherence, and terms associated with the psychometric properties of instruments (validity, quality and reproducibility). In order to increase the sensibility of the search strategy, searches were conducted using the thesaurus of each of the databases selected and keywords—in the title and abstract—associated with the search terms (figure 1). The electronic searches were complemented by manual searches ${ }^{40}$ in international journals with regard to their relevance and frequency in the publication, by new searches on PubMed under the names of the identified MD score and under the names of the authors who had created or adapted them, and by the references of the articles that complied with the inclusion criteria. Abstracts from congresses and grey literature were excluded. 


\section{Inclusion criteria}

All original articles that examined some aspects of the conceptual suitability (conceptual and measurement model, cultural and linguistic adaptation), applicability (demands of the administrator/respondent, alternative forms and interpretability) or psychometric properties (reliability, validity and responsiveness) of the MD adherence score in English or Spanish published until 31 December 2015 (from January 1980 to 31 December 2015) were included.

\section{Exclusion criteria}

The studies where MD adherence scores were administered but did not bring forward any evidence about their performance related to conceptual suitability, applicability or psychometric properties were excluded.

\section{Selection of studies}

Two reviewers (RF-C and AZ-M) assessed the titles and abstracts to determine their inclusion or exclusion from the review. The reviewers worked independently, and if they were in disagreement a third reviewer (MJC-M) would resolve the disagreement or recommend reading the whole article.

\section{Data extraction}

Information was extracted by the same researchers (MJC-M, RF-C and AZ-M), who had independently carried out the selection of original articles, resolving disagreements through consensus with a third person. The information extracted was divided into two sections: information about the characteristics of the study and the sample, and information about the measurement scales. The first section included the characteristics of the study and the sample (inclusion criteria, sample size and origin of the population).

Information relating to the scales was extracted in accordance with the quality criteria defined by the SAC of the Medical Outcomes Trust for measurement of health results and the quality criteria recommended by Terwee. ${ }^{36-39}$ In order to facilitate understanding, the eight attributes of the SAC were included in three groups of information ${ }^{41}$ : (1) conceptual suitability (conceptual and measurement model, cultural and linguistic adaptation); (2) applicability (demands of the administrator/ respondent, alternative forms and interpretability); and (3) psychometric properties (reliability, validity and responsiveness). Onlinesupplementary table 1 sets out the quality criteria used and their measurement values. Finally, a summary table was created providing evidence from all the scales, with a view to synthesising information on the basis of the criteria developed by McDowell. ${ }^{42}$ The following assessment criteria were established: (1) process of cross-transcultural adaptation (?: not reported; +: translation only; ++: translation-back translation; +++: translation-back translation and pilot test); (2) applicability (?: not reported; +: data about the process of administration and interviewing; ++: visual material about foods and training of interviewers; +++: normative data); (3) reliability (?: not reported or weak associations of some aspects of internal consistency reported; +: alphacoefficient of internal consistency, or intrarater or inter-rater reliability reported; ++: alphacoefficient or interclass correlation coefficients (ICC) or correlated coefficient $>0.70$; and (4) validity (?: not reported; +: evidence from criterion or construct validity; ++: evidence from criterion and construct validity).

\section{RESULTS}

\section{Search results}

A total of 56 articles met the inclusion criteria, which were reduced to 52 once the duplicates had been removed (figure 2). In addition, 19 of these articles were excluded after reviewing the title and the abstract because they did not meet the inclusion criteria. Finally a further six articles were excluded because they did not use specific MD adherence scores in their methodology. Therefore, 27 articles were included in the review, from which $28 \mathrm{MD}$ adherence scores were used.

\section{Characteristics of included studies}

The designs of the studies included were principally observational (12 cohort studies, ${ }^{14} 1626$ 28-31 43-47 1 case and control study, ${ }^{34} 14$ descriptive studies 61112293233 48-55 and 1 intervention study ${ }^{56}$ ). A total of 17 studies focused on the general population, ${ }^{6} 142629$ 32-34 46-50 52-56 3 on the elderly, ${ }^{30} 43452$ on children, ${ }^{11} 121$ on university students ${ }^{16}$ and 1 on pregnant women. ${ }^{31}$ Finally, three of them did not indicate the target population of the scores. ${ }^{162844}$ With respect to sample size, the scores created by Trichopoulou et $a l^{1443}$ were developed using large samples: 22043 and 74607 people, respectively. There were three studies with a sample size of $<150$ people. $^{295156}$

\section{Conceptual suitability}

Online supplementary table 2,3 summarise key data regarding the conceptual suitability of the different scores: the context in which they were applied, content validity and cross-cultural adaptation process. The scores were listed according to their conceptual model and measurement. The majority of the scores $(\mathrm{n}=18)^{61114162629-3443-45484951}$ were based on positive and negative components of MD. Five of them were based on the structure of the MD food pyramid, ${ }^{28} 52-5456$ three on the general characteristics of $\mathrm{MD}^{464755}$ and one on the Diet Quality Index. ${ }^{12}$ As a fundamental model, the scores created by Trichopoulou et $a l^{143043}$ have been the most widely used, with six scores being created on the basis of their components. 162629314550

Although there is no consensus on the meaning of the ratings, as a general rule, interpretation of these scales is positive for healthy items and negative for unhealthy items, with high scores indicating good adherence to the MD and low scores, poor adherence. Only the scores created by Scali et $a l^{48}$ and Gerber ${ }^{49}$ provide inverted 


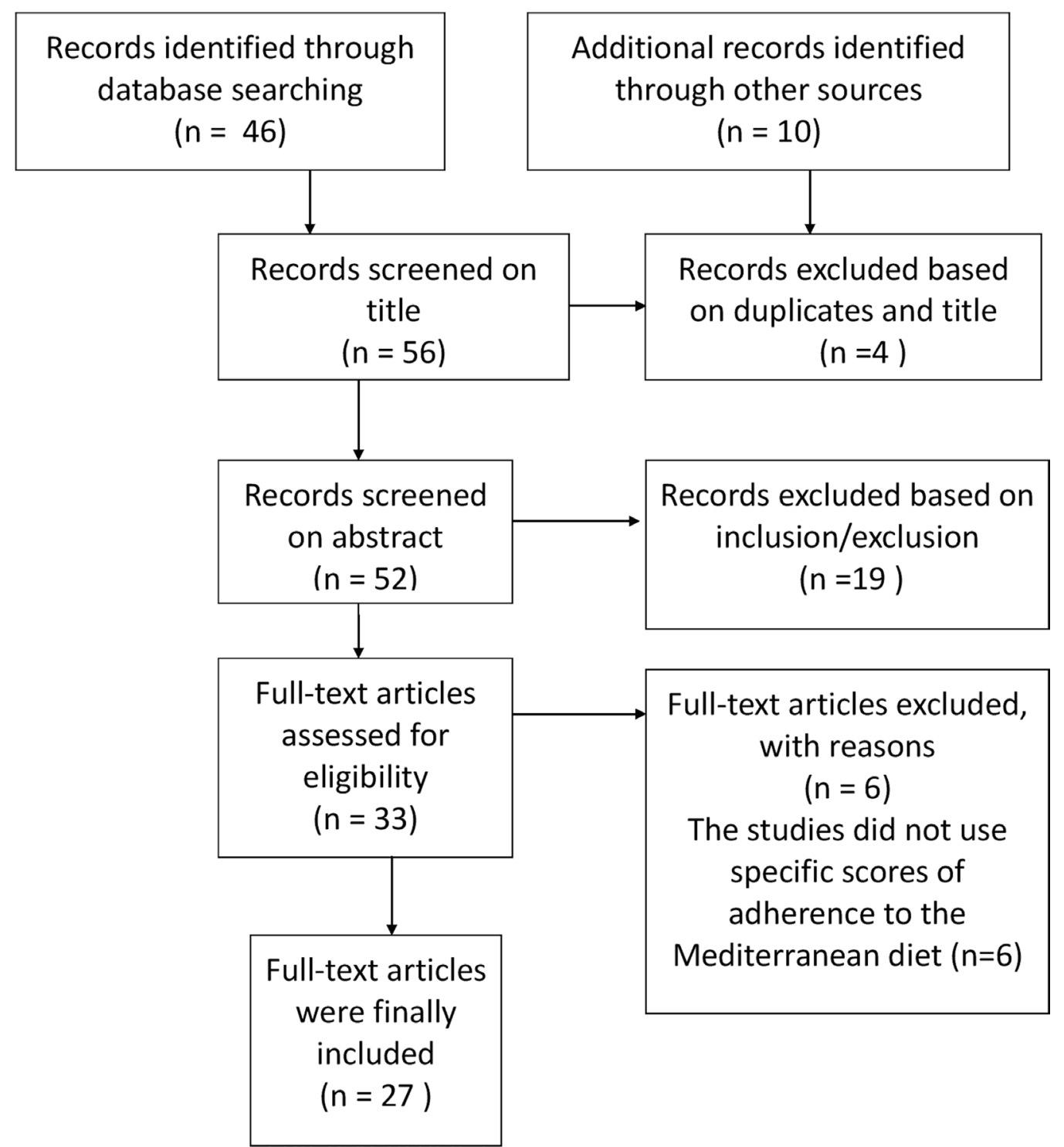

Figure 2 Search and inclusion process flow chart of studies to include in systematic review of the evaluation of Mediterranean diet adherence scores: identification, screening, eligibility and inclusion.

scores, where high scores indicate low adherence and low scores indicate good adherence (online supplementary table 2).

The majority of the scores were developed in Mediterranean countries: Spain $(n=14),{ }^{11} 1216262931-3447505354$ Greece $(n=3),{ }^{61430}$ Italy $(n=2){ }^{46} 47$ and France $(n=2) .{ }^{48} 49$ The remainder were developed in Canada $(n=1),{ }^{56}$ other European countries $(n=3),{ }^{43-45}$ Japan $^{52} 55$ and the USA $(n=2)^{2855}$ (see online supplementary table 2 ).

Regarding the context of application (online supplementary table 3), 12 of the 28 scores analysed were applied to the general population, ${ }^{16} 2645-4749-54566$ in primary care, ${ }^{62932434855} 3$ in hospital care, ${ }^{3133} 346$ in the community 61114283055 and 1 in sports clubs. ${ }^{12}$ The scores developed by Panagiotakos et $a t^{6}$ and Woo et a $t^{55}$ are used in the context of primary care and also in the community.

None of the MD adherence scores detail the process of cross-transcultural adaptation. The majority of the scores come from the one Food Frequency Questionnaire
(FFQ) previously validated for the population studied; however, in the original studies of this instrument (FFQ), the process of cross-cultural adaptation has not been detailed.

With regard to content validity, the majority of scores based on negative and positive components $^{614262931434550}$ are created in function of the scores developed by Trichopoulou and colleagues. ${ }^{30}$ Scores of the MD pyramid are based on the pyramid elaborated by Bach-Faig and colleagues. ${ }^{57}$ The rest of the scores are founded in general references of the MD pattern.

\section{Applicability}

Relating to the applicability of the MD adherence scores, with the exception of the score created by Woo et $a l^{55}$ who did not specify the method of administration, all diet questionnaires were administered by trained interviewers. Regarding the source of information, all of the scores were answered by the patients/participants (not by a 
proxy), except for the scores created by Serra-Majem et $a l^{11}$ and Woo et $a l^{55}$ The participants completed the diet questionnaires, and the researchers calculated the MD score. The time taken to administer and complete the items was not reported for any of the scales analysed. The only information provided was the existence of trained staff to administer the questionnaires. Regarding the completion of questionnaires about food intake, only five of the scores ${ }^{614264855}$ indicate having used a portion size booklets in order to help participants estimate their food intake more accurately. None of the studies provided normative data about the scores.

\section{Psychometric properties}

With regard to internal consistency (online supplementary table 4 ), only the score created by Sotos-Prieto et $a l^{54}$ provided a Cronbach alpha coefficient of 0.75 . Given that the authors do not report item-test correlation coefficients, the degree of association between the items and the overall score was taken into account. The association between high global scores and the consumption of fruits, vegetables, nuts and olive oil ${ }^{614283148-5053}$ was reported in eight of the scores. With respect to equivalence, only the two scores created by Benítez-Arciniega $e t a l^{29}$ provided data on equivalence (inter-rater) (ICC modified Mediterranean Diet Score $=0.48$ and ICC Mediterranean-Like Diet Score $=0.62)$. None of the scores reported on test-retest reliability (intrarater).

Relating to criterion validity, predictive and concurrent validity were evaluated (online supplementary tables $5 \mathrm{a}$ and $5 \mathrm{~b}$ ). Predictive validity was reported in 5 of the 28 scores, using mortality rate or cardiovascular events as the predictive criterion. High MD adherence scores were associated with a significant reduction in the risk of mortality OR (0.64-0.83). ${ }^{14} 26304345$ In only one study was the MD adherence score associated with cardiovascular events (increase adherence $=40 \%$ lower cardiovascular risk; $\mathrm{P}<0.001) .{ }^{26}$ Concurrent validity was reported in 10 of the 28 scores; adherence to MD was associated inversely with clinical and biological markers of cardiovascular disease risk, ${ }^{633} 345256$ body mass index, waist-hip and weight. ${ }^{283132505356}$ Finally, for the analysis of construct validity, the authors linked scores with other variables and scales (online supplementary table 6). All measurement scores, with the exception of those developed by Trichopoulou et $a l^{143043}$ and Alberti-Fidanza et $a l^{46}$ displayed a relationship with other health and dietary behaviour variables (sociodemographic variables, level education, physical activity, habit of smoking, alcohol consumption, age, antioxidants, energy and food intake). As for the relationship with other scales, only the scores created by Buckland et $a l,{ }^{26}$ Mariscal-Arcas $e t a l,{ }^{31}$ Knoops et $a l^{45}$ and Monteagudo et $a \tilde{l}^{3}$ indicate comparison with the MD adherence score created by Trichopoulou et al, ${ }^{30}$ obtaining high levels of agreement $(70 \%)$.

With regard to the measure of responsiveness, none of the scores provided an estimation of a statistic capable of measuring effect size. Only the score developed by Goulet et $a \tilde{p}^{\tilde{6}}$ examined the effect of a nutritional intervention, in which MD adherence scores increased significantly from $21.1 \pm 3.6$ in week 0 to $28.6 \pm 4.4(\mathrm{P}<0.001)$ after 6 weeks of intervention.

Online supplementary table 7 presents the MD summary scores. Only four scores did not provide any information about the cross-transcultural process. ${ }^{14} 313247$ The scores developed by Panagiotakos et $a l,{ }^{6}$ Trichopoulou et $a l,{ }^{14}$ Scali et $a l l^{48}$ Gerber $^{49}$ and Woo et $a l^{55}$ obtained the best evaluations in terms of applicability. The score created by Sotos-Prieto et a $\tilde{l}^{4}$ was the instrument with the most and best evidence on reliability. Information about validity was provided for most of the scores, but concurrent and predictive validity were only reported for the scores created by Panagiotakos et $a l,{ }^{6}$ Schröder et al, ${ }^{32}$ MartínezGonzález et $a l^{33}{ }^{34}$ and Knoops et al. ${ }^{45}$ The results indicate that the scores with the best overall evaluation were those created by Panagiotakos et al, ${ }^{6}$ Buckland $e t a l^{26}$ and SotosPrieto et $a l^{54}$ However, only the study by Sotos-Prieto et $a e^{4}$ provided information about reliability.

\section{DISCUSSION}

The review conducted here included 27 references and identified $28 \mathrm{MD}$ adherence scores used internationally. The evidence obtained from these studies has been evaluated based on conceptual suitability, applicability and psychometric properties. The results reveal that evidence is scarce, and that very few scores fulfil psychometric properties and applicability parameters typically associated with scales/indices. The scores developed by Panagiotakos et al, ${ }^{6}$ Buckland $e t a l^{26}$ and Sotos-Prieto et $a \tilde{l}^{4}$ provide the most information. However, as with the other scores analysed, none of them provide complete information about the process of transcultural adaptation used. The scores reviewed here only specify that a previously validated FFQ for the original population has been used, but do not provide the transcultural adaptation of these dietary questionnaires (translation, back translation and pilot study). The Scientific Committee of the Medical Outcomes Trust ${ }^{39}$ considers cultural and linguistic adaptation to be an especially important criterion in achieving linguistic and cultural equivalence with an original instrument.

Applicability is one of the sections that present the most information gaps. None of the scores report on normative data, and only five of them ${ }^{61425} 4855$ provide detailed information about the administration process using photographic and visual material to obtain information as close to reality as possible.

The data about reliability are the most deficient. To ascertain the degree to which all the items on a scale measure the same construct, internal consistency must be measured. In this case, the score created by Sotos-Prieto $e t a l^{4}$ is the only one that provides information about this topic, through the Cronbach alpha value. The degree of association between the scores obtained and the items included on the instrument has been taken into account, 
but this information cannot be considered a quality itemtest measure of reliability. Regarding reliability data, only the two scores created by Benítez-Arciniega et $a l^{29}$ display test-retest reliability and equivalence reliability.

Validity was the most widely reported property. Only the scores created by Benítez-Arciniega $e t$ a ${ }^{29}$ did not include any information about validity. In the scientific literature, there are different gold standards to evaluate criterion validity, such as clinical and biological markers for concurrent validity, and adverse events for predictive validity. However, the best gold standard, 'observation of food intake', has not been used in any of the studies. In some of the studies analysed, ${ }^{2631}$ the gold standard used is the score created by Trichopoulou et al, ${ }^{30}$ obtaining agreement levels of close to $70 \%$ with the original, considered here to provide construct validity. This one was the first score used to measure levels of adherence to MD, but it cannot be considered a gold standard, since there is new evidence indicating changes in food and diet patterns. It should also be pointed out that no confirmatory analysis was conducted in relation to the structure of the instruments.

It has been consistently demonstrated that MD helps to protect against cardiovascular disease, inflammatory and metabolic diseases, as well as numerous chronic degenerative diseases ${ }^{123558-63}$; nevertheless, the protective effect of MD is very different across the studies. ${ }^{354}$ Consequently, a large number of MD adherence scores are being created to ascertain the relationship between diet and health. However, recent publications indicate that some of these scores do not offer strong predictive capacity regarding mortality or disease, thus questioning the quality. 136465 This observation is borne out by the findings of this study, which has shown that the majority of the scores analysed are lacking in information about the quality attributes of the scales.

For all of the above reasons, greater attention must be paid to the way in which these scores have been created. First, a common criterion should be established to identify the components that make up MD. Second, different elements need to be unified: the number of components (nutrients, foods or food groups), classification categories for each population, measurement scale, statistical parameters (mean, median, tertiles and so on) and the contribution of each component (positive or negative) to the score total. ${ }^{15} 356667$ Finally, given the great heterogeneity of MD in different countries, further confirmatory analyses are required using biomarkers with a view to validating said dietary pattern.

\section{Strengths and limitations}

Although the data are conclusive regarding the lack of quality of MD adherence scores and the need to improve the measurement of MD adherence, it is important to take into consideration the limitations of this review, which are related to the process of bibliographic searches, derived from the electronic search and retrieval of documents. In order to control this limitation, multiple synonyms of the search terms were used, and complementary searches of prestigious journals and bibliographic references were also conducted. Furthermore, this review only took account of studies wherein the main objective was to develop or examine data about the applicability or psychometric properties of an MD adherence score. It could produce an underestimation of the predictive and/or concurrent validity, which are the most frequently analysed in longitudinal studies on MD adherence scores.

In conclusion, the use of scores to measure adherence to $\mathrm{MD}$ is a very useful tool for identifying the dietary patterns of the population. However, our results point out that fewer of the analysed scores suit the quality criteria. The scores developed by Panagiotakos et al, ${ }^{6}$ Buckland $e t a l^{26}$ and Sotos-Prieto et a $a b^{54}$ have obtained better evidence, although they have not been considered as gold standard because they do not fit all of the quality criteria. As a consequence, it could be possible that the employed scores to evaluate the relationship between MD and health do not present a good predictive ability, originating significant bias in the obtained results. For all these reasons, further information is required about the scores that currently exist, and/or new instruments with better concept grounded must be developed. Future research should focus on improving the psychometric properties of the MD adherence scores and analysing the concordance between these instruments in compliance with the normative quality criteria.

Contributors Conceived and designed the experiments: AZ-M, MJC-M, RF-C. Analysed the data: AZ-M, MJC-M, RF-C, JAH-S, AL-P. Wrote the paper: AZ-M, MJC-M, RF-C, JAH-S, AL-P. Data interpretation and critical revision of manuscript: AZ-M, MJC-M, RF-C, JAH-S, AL-P. All authors reviewed and approved the manuscript.

Funding This research received no specific grant from any funding agency in the public, commercial or not-for-profit sectors.

Competing interests None declared.

Patient consent Not required.

Provenance and peer review Not commissioned; externally peer reviewed. Data sharing statement No additional data are available.

Open Access This is an Open Access article distributed in accordance with the Creative Commons Attribution Non Commercial (CC BY-NC 4.0) license, which permits others to distribute, remix, adapt, build upon this work non-commercially, and license their derivative works on different terms, provided the original work is properly cited and the use is non-commercial. See: http://creativecommons.org/ licenses/by-nc/4.0/

(c) Article author(s) (or their employer(s) unless otherwise stated in the text of the article) 2018. All rights reserved. No commercial use is permitted unless otherwise expressly granted.

\section{REFERENCES}

1. Sofi F, Cesari F, Abbate R, et al. Adherence to Mediterranean diet and health status: meta-analysis. BMJ 2008;337:a1344.

2. Sofi F, Macchi C, Abbate R, et al. Mediterranean diet and health. Biofactors 2013;39:335-42.

3. Kesse-Guyot E, Ahluwalia N, Lassale C, et al. Adherence to Mediterranean diet reduces the risk of metabolic syndrome: a 6-year prospective study. Nutr Metab Cardiovasc Dis 2013;23:677-83.

4. Esposito K, Maiorino MI, Bellastella G, et al. Mediterranean diet for type 2 diabetes: cardiometabolic benefits. Endocrine 2017;56. 
5. Murtaugh MA, Herrick JS, Sweeney C, et al. Diet composition and risk of overweight and obesity in women living in the southwestern United States. J Am Diet Assoc 2007;107:1311-21.

6. Panagiotakos DB, Pitsavos C, Stefanadis C. Dietary patterns: a Mediterranean diet score and its relation to clinical and biological markers of cardiovascular disease risk. Nutr Metab Cardiovasc Dis 2006;16:559-68.

7. Kim J, Jo I, Grains Jl. Grains, vegetables, and fish dietary pattern is inversely associated with the risk of metabolic syndrome in South korean adults. J Am Diet Assoc 2011;111:1141-9.

8. Pitsavos C, Panagiotakos DB, Tzima N, et al. Adherence to the Mediterranean diet is associated with total antioxidant capacity in healthy adults: the ATTICA study. Am J Clin Nutr 2005;82:694-9.

9. .Bihuniak JD, Ramos A, Huedo-Medina T, et al. Adherence to a Mediterranean-Style Diet and Its Influence on Cardiovascular Risk Factors in Postmenopausal Women. J Acad Nutr Diet 2016;116:1767-75

10. Tyrovolas S, Panagiotakos DB. The role of Mediterranean type of diet on the development of cancer and cardiovascular disease, in the elderly: a systematic review. Maturitas 2010;65:122-30.

11. Serra-Majem L, Ribas L, Ngo J, et al. Food, youth and the Mediterranean diet in Spain. Development of KIDMED, Mediterranean Diet Quality Index in children and adolescents. Public Health Nutr 2004;7:931-5.

12. Mariscal-Arcas M, Rivas A, Velasco J, et al. Evaluation of the Mediterranean Diet Quality Index (KIDMED) in children and adolescents in Southern Spain. Public Health Nutr 2009;12:1408-12.

13. Sofi F, Macchi $\mathrm{C}$, Abbate R, et al. Mediterranean diet and health status: an updated meta-analysis and a proposal for a literaturebased adherence score. Public Health Nutr 2014;17:2769-82.

14. Trichopoulou A, Costacou T, Bamia C, et al. Adherence to a Mediterranean diet and survival in a Greek population. N Engl J Med 2003;348:2599-608.

15. Bach A, Serra-Majem L, Carrasco JL, et al. The use of indexes evaluating the adherence to the Mediterranean diet in epidemiological studies: a review. Public Health Nutr 2006;9:132-46.

16. Sánchez-Villegas A, Martínez JA, De Irala J, et al. Determinants of the adherence to an "a priori" defined Mediterranean dietary pattern. Eur J Nutr 2002;41:249-57.

17. Haveman-Nies A, de Groot L, Burema J, et al. Dietary quality and lifestyle factors in relation to 10-year mortality in older Europeans: the SENECA study. Am J Epidemiol 2002;156:962-8.

18. Knoops KTB, de Groot LCPGM, Kromhout D, et al. Mediterranean diet, lifestyle factors, and 10-year mortality in elderly European men and women: the HALE project. JAMA 2004;292:1433-9.

19. Hubert HB, Feinleib M, McNamara PM, et al. Obesity as an independent risk factor for cardiovascular disease: a 26-year follow-up of participants in the Framingham Heart Study. Circulation 1983;67:968-77

20. Tyrovolas S, Polychronopoulos E, Bountziouka V, et al. Level of adherence to the Mediterranean diet among elderly individuals living in Mediterranean islands: nutritional report from the Medis Study. Ecol Food Nutr 2009;48:76-87.

21. Couto E, Boffetta P, Lagiou P. Mediterranean dietary pattern and risk of breast cancer. Br J Cancer 2011;104:1493-9.

22. Yusuf S, Hawken S, Ounpuu S, et al. Effect of potentially modifiable risk factors associated with myocardial infarction in 52 countries (the INTERHEART study): case-control study. Lancet 2004;364:937-52.

23. Sánchez-Taínta A, Estruch R, Bulló M, et al. Adherence to a Mediterranean-type diet and reduced prevalence of clustered cardiovascular risk factors in a cohort of 3,204 high-risk patients. Eur J Cardiovasc Prev Rehabil 2008;15:589-93.

24. Crous-Bou M, Fung TT, Prescott J, et al. Mediterranean diet and telomere length in Nurses' Health Study: population based cohort study. BMJ 2014;349:g6674.

25. Buckland G, Agudo A, Travier N, et al. Adherence to the Mediterranean diet reduces mortality in the Spanish cohort of the European Prospective Investigation into Cancer and Nutrition (EPICSpain). Br J Nutr 2011;106:1581-91.

26. Buckland G, González CA, Agudo A, et al. Adherence to the Mediterranean diet and risk of coronary heart disease in the Spanish EPIC Cohort Study. Am J Epidemiol 2009;170:1518-29.

27. Bosetti C, Gallus S, Trichopoulou A, et al. Influence of the Mediterranean diet on the risk of cancers of the upper aerodigestive tract. Cancer Epidemiol Biomarkers Prev 2003;12:1091-4.

28. Rumawas ME, Dwyer JT, McKeown NM, et al. The development of the Mediterranean-style dietary pattern score and its application to the American diet in the Framingham Offspring Cohort. J Nutr 2009;139:1150-6.
29. Benítez-Arciniega AA, Mendez MA, Baena-Díez JM, et al. Concurrent and construct validity of Mediterranean diet scores as assessed by an FFQ. Public Health Nutr 2011;14:2015-21.

30. Trichopoulou A, Kouris-Blazos A, Wahlqvist ML, et al. Diet and overall survival in elderly people. BMJ 1995;311:1457-60.

31. Mariscal-Arcas M, Rivas A, Monteagudo C, et al. Proposal of a Mediterranean diet index for pregnant women. Br J Nutr 2009;102:744-9.

32. Schröder H, Fitó M, Estruch R, et al. A short screener is valid for assessing Mediterranean diet adherence among older Spanish men and women. J Nutr 2011;141:1140-5.

33. Martínez-González MA, Fernández-Jarne E, Serrano-Martínez $\mathrm{M}$, et al. Development of a short dietary intake questionnaire for the quantitative estimation of adherence to a cardioprotective Mediterranean diet. Eur J Clin Nutr 2004;58:1550-2.

34. Martínez-González MA, Fernández-Jarne E, Serrano-Martínez M, et al. Mediterranean diet and reduction in the risk of a first acute myocardial infarction: an operational healthy dietary score. Eur J Nutr 2002;41:153-60.

35. Hernández-Ruiz A, García-Villanova B, Guerra Hernández EJ, et al. Description of indexes based on the ADHERENCE TO THE mediterranean dietary pattern: a review. Nutr Hosp 2015;32:1872-84.

36. Valderas JM, Ferrer M, Alonso J. [Health-related quality of life instruments and other patient-reported outcomes]. Med Clin 2005;125 Suppl 1:56-60.

37. Cabañero-Martínez MJ, Muñoz-Mendoza CL, Richart-Martínez M, et al. [Review of the attributes of patient-based health outcomes instruments]. Enferm Clin 2008;18:84-90.

38. Terwee CB, Bot SD, de Boer MR, et al. Quality criteria were proposed for measurement properties of health status questionnaires. $J$ Clin Epidemiol 2007;60:34-42.

39. Aaronson N, Alonso J, Burnam A, et al. Assessing health status and quality-of-life instruments: attributes and review criteria. Qual Life Res 2002;11:193-205.

40. McDonald SJ, Lefebvre C, Clarke MJ. Identifying reports of controlled trials in the BMJ and the Lancet. BMJ 1996;313:1116-7.

41. VanSwearingen JM, Brach JS. Making geriatric assessment work: selecting useful measures. Phys Ther 2001;81:1233-52.

42. McDowell L. Measuring health: a guide to rating scales and questionnaires. 3nd ed. New York: Oxford University press, 2006.

43. Trichopoulou A, Orfanos P, Norat T, et al. Modified Mediterranean diet and survival: EPIC-elderly prospective cohort study. BMJ 2005;330:991.

44. Trichopoulos D, Lagiou P. Mediterranean diet and overall mortality differences in the European Union. Public Health Nutr 2004;7:949-51.

45. Knoops KT, de Groot LC, Kromhout D, et al. Mediterranean diet, lifestyle factors, and 10-year mortality in elderly European men and women: the HALE project. JAMA 2004;292:1433-9.

46. Alberti-Fidanza $A$, Fidanza $F$, Chiuchiù MP, et al. Dietary studies on two rural Italian population groups of the Seven Countries Study. 3. Trend Of food and nutrient intake from 1960 to 1991. Eur J Clin Nutr 1999;53:854-60.

47. Alberti-Fidanza A, Fidanza F. Mediterranean Adequacy Index of Italian diets. Public Health Nutr 2004;7:937-41.

48. Scali J, Richard A, Gerber M. Diet profiles in a population sample from Mediterranean southern France. Public Health Nutr 2001;4:173-82.

49. Gerber M. Qualitative methods to evaluate Mediterranean diet in adults. Public Health Nutr 2006;9:147-51.

50. Schröder H, Marrugat J, Vila J, Covas MI, et al. Adherence to the traditional mediterranean diet is inversely associated with body mass index and obesity in a spanish population. J Nutr 2004;134:3355-61.

51. Schröder H, Benitez Arciniega A, Soler C, et al. Validity of two short screeners for diet quality in time-limited settings. Public Health Nutr 2012;15:618-26.

52. Kanauchi M, Kanauchi K. Diet quality and adherence to a healthy die in Japanese male workers with untreated hypertension. BMJ Open 2015;5:e008404.

53. Monteagudo C, Mariscal-Arcas M, Rivas A, et al. Proposal of a Mediterranean Diet Serving Score. PLoS One 2015;10.

54. Sotos-Prieto M, Moreno-Franco B, Ordovás JM, et al. Design and development of an instrument to measure overall lifestyle habits for epidemiological research: the Mediterranean Lifestyle (MEDLIFE) index. Public Health Nutr 2015;18:959-67.

55. Woo J, Woo KS, Leung SS, et al. The Mediterranean score of dietary habits in Chinese populations in four different geographical areas. Eur J Clin Nutr 2001;55:215-20.

56. Goulet J, Lamarche B, Nadeau G, et al. Effect of a nutritional intervention promoting the Mediterranean food pattern on plasma lipids, lipoproteins and body weight in healthy French-Canadian women. Atherosclerosis 2003;170:115-24. 
57. Bach-Faig A, Berry EM, Lairon D, et al. Mediterranean diet pyramid today. Science and cultural updates. Public Health Nutr 2011;14:2274-84. Davidson SS and Passmore R. Human nutrition and dietetics. Edinburgh: Churchill Livingtone 1979.

58. Serra-Majem L, Bach A, Roman B. Recognition of the mediterranean diet: going a step further. Public Health Nutr 2006;9:101-2.

59. Mitsou EK, Kakali A, Antonopoulou S, et al. Adherence to the mediterranean diet is associated with the gut microbiota pattern and gastrointestinal characteristics in an adult population. Br J Nutr 2017;117:1645-55.

60. Barrea L, Muscogiuri G, Macchia PE, et al. Mediterranean diet and phase angle in a sample of adult population: results of a pilot study. Nutrients 2017;9:E151.

61. Park YM, Zhang J, Steck SE, et al. Obesity mediates the association between mediterranean diet consumption and insulin resistance and inflammation in US adults. J Nutr 2017;147:563-71.
62. Maiorino MI, Bellastella G, Petrizzo M, et al. Mediterranean diet cools down the inflammatory milieu in type 2 diabetes: the MÉDITA randomized controlled trial. Endocrine 2016;54:634-41.

63. Vallianou NG, Georgousopoulou E, Evangelopoulos AA, et al. Inverse relationship between adherence to the mediterranean diet and serum cystatin C Levels. Cent Eur J Public Health 2017;25:240-4.

64. D'Alessandro A, De Pergola G, Diet M. Mediterranean diet and cardiovascular disease: a critical evaluation of a priori dietary indexes. Nutrients 2015;7:7863-88.

65. Waijers PM, Feskens EJ, Ocké MC. A critical review of predefined diet quality scores. Br J Nutr 2007;97:219-31.

66. Bamia C, Trichopoulos D, Ferrari P, et al. Dietary patterns and survival of older Europeans: the EPIC-Elderly Study (European Prospective Investigation into Cancer and Nutrition). Public Health Nutr 2007:10:590-8.

67. van Dam RM. New approaches to the study of dietary patterns. $\mathrm{Br} J$ Nutr 2005;93:573-4. 